\title{
TRIZ-Based Guidelines for Eco-Improvement
}

\author{
Davide Russo *(D) and Christian Spreafico \\ Department of Management, Information and Production Engineering, University of Bergamo, \\ 24044 Dalmine (Bg), Italy; christian.spreafico@unibg.it \\ * Correspondence: davide.russo@unibg.it
}

Received: 23 February 2020; Accepted: 19 April 2020; Published: 22 April 2020

check for updates

\begin{abstract}
This paper proposes a set of Eco-guidelines for supporting designers in developing new greener products and processes. The first requirement that a guideline should have is to be sufficiently general to cover every kind of problem and at the same time sufficiently specific to bring the user closer to the solution without requiring too much personal inspiration. This balance was searched by adopting one of the most known systematic innovation techniques: TRIZ (Russian acronym of Theory of Inventive Problem Solving). In the literature, there are many examples of integrations between Eco-guidelines and problem-solving methods, but the solutions that are suggested, however effective, are not necessarily eco-friendly. To overcome this problem, the authors propose a rigorous ontology indicating how to apply a specific problem-solving strategy onto a specific part of the problem, trying to make the user aware of the environmental consequences of his design changes. The result of this work is a set of 59 guidelines. The article explains the birth of each guideline, the way in which they were adapted with respect to the known technique, and the motivation for which they should generate greener solutions, in light of the results of an experiment involving engineering students in real industrial cases.
\end{abstract}

Keywords: Ecodesign; Eco-guidelines; problem-solving; TRIZ

\section{Introduction}

Nowadays, the literature counts more than 12,000 scientific papers and books (indexed in Scopus) about Ecodesign. Within this pool, about 25\% propose Eco-improvement methods, guidelines, checklists, mainly published on Journal of Cleaner Production and International Journal of Life Cycle Assessment, with a constant growth trend over the last 10 years (80 documents in 2009, 331 in 2018).

These methods have been classified according to different criteria. The integrations with other methods, tools and theories (e.g., [1,2]), such as Genetic Algorithms, Fuzzy Logic, Monte Carlo simulation, Analytic Hierarchy Process, and Informatic frameworks. The level of involvement of the designer (e.g., [3]), to whom the methods provide ready-to-use solutions, examples from other fields of application or suggestions for supporting her/him personally developing the solutions. The level of preparation of the designer (e.g., [4]) in terms of learning ability, personal background and the level of experience about the considered methods. The phase of product lifecycle to which the suggestions are more focused and their level of specificity (e.g., [5]). The qualitative of the quantitative nature of the provided solutions and examples [6]. The adherence of the methods with ergo-ecology principles (e.g., [7]) in terms of eco-efficiency, eco-effectiveness, eco-productivity, green ergonomics, sustainable development, wellbeing and human ecology.

It is difficult to catalog all the methods proposed in these years, and it is even more difficult establishing which of these are more widespread and representative. This is confirmed by the surveys counting over 150 methods by [8], or a more recent survey by [2] comparing 124 independent methods. 
Such a large and growing number of publications can be explained by the fact that there is still no method/set of guidelines that has established itself as a reference point; on the contrary, there are many problems still open [9-12].

To be effective, the guidelines must be sufficiently general to cover every application context and at the same time sufficiently specific to bring the user closer to the solution, without requiring too much personal inspiration. It is crucial to find strategies for solving the conflict in functional/environmental requirements and the best trade-off identification [2].

In order to find this balance, there are many examples of eco-guidelines integrating other methods, like TRIZ [13], Quality Function Deployment-QFD [14] and Case-Based Reasoning-CBR (e.g., [15,16] While in [17], the same authors proposed a set of 300 Eco-guidelines, based on TRIZ [18], called ITree. The experience gained by applying ITree in numerous applications in different industrial contexts has been fundamental to confirm that this direction is promising but also that, unfortunately, problem-solving methods support users in inventing good but not necessarily greener solutions.

In order to solve this problem, this paper proposes a new set of guidelines, always based on TRIZ but totally rewritten for making the user aware of the environmental consequences of its design changes.

The reworking of ITree led to a brand-new set of guidelines (only 59 guidelines). They are conceived for people not skilled in art and, in comparison with our previous works $([13,18])$ and other sets of eco-guidelines $([14,15,17])$, they force the user to work in a more targeted way within problem-space, providing suggestions on how to implement an Ecodesign strategy at a much higher level than the other methods. Differently to other approaches, the proposed method stresses the concepts related to operating space/time and the use of resources more.

Testing the guidelines with students on industrial case studies has enabled these qualities to be verified and convinced a consulting firm to propose them to small and medium enterprises as a fixed catalog service.

\section{State of the Art}

Among the several methods for Ecodesign, those particularly interesting for this paper propose integrations with theories of inventive problem-solving, and in particular with TRIZ. [19] and [20] affirm that TRIZ can help the designers in overcoming some critical issues during Eco-product development by means of potential innovative solutions, or even before, according to [21], by supporting the Anticipatory Failure Determination. [22] instead states that TRIZ integration is valuable since it does not require an encyclopedic knowledge of field-specific technology and it enables the expansion of the scope of problem solutions beyond the skills of the team members. Other advantages include reducing the time of the design and development phases (e.g., [16]), increasing product quality without burdening costs (e.g., [1]), and minimizing industrial waste and emissions through energy efficiency (e.g., [23]).

Among the several integrations between TRIZ and Ecodesign, we can identify three main research fields.

Some authors suggested that TRIZ tools are most suitable for improving the sustainability of a phase of the product lifecycle and/or a specific problem or strategy. The Evolution Trends (e.g., Dematerialization) are used by [24] for improving the design phase through mass reduction and geometry modification, while the Contradiction Matrix and the Principles are exploited by [25] and [26] for improving the use phase (i.e., reducing consumption) and by [27] and [28] for the end-of-life (i.e., disassembly).

Other authors proposed suggestions and frameworks for guiding the designers to exploit TRIZ tools in a most proficient manner for Ecodesign. [29] introduced a set of guidelines for explaining how the Laws of Technical System Evolution could be used to assess the value of existing solutions, to understand the most promising directions of improvement and to improve them. [30] introduced a life cycle planning methodology for guiding the application of the Contradiction Matrix for solving design contradictions between quality, costs and environmental aspects. 
Finally, there are a restricted number of attempts focused in customizing the TRIZ tools (e.g., [16,31] or the entire methodology (e.g., [32]), by maintaining the theoretical content and aligning the TRIZ jargon to Ecodesign, with the aim to facilitate the approach for not-expert users.

However, although such approaches can easily lead to more innovative solutions, these are not necessarily greener. This is because, according to [33] and [34], at the same time, general purpose idea generation tools do not usually show any specific preference to sustainable aspects, since their overall purpose is product success and the identification of unexplored market opportunities. Therefore, the attention to sustainability is random, not taken for granted and presumably dependent on designers' sensibilities towards environmental and human problems. This paper is also supported by different studies that quantitatively assessed the solutions resulting from TRIZ tools. According to [24], solutions deriving from the same TRIZ tools (i.e., the trends of evolution) and concerning different aspects (e.g., materials and aesthetics) are better in certain cases than traditional solutions. While [25] instead positively evaluated the solution by limiting only to the use phase of the product lifecycle or assessing a reduction of the consumption without considering the impact deriving from their implementation during manufacturing. Finally, there is also the negative qualitative assessment concerning the perception of the sustainability of those TRIZ-derived solutions, which typically ignore social aspects about sustainability, e.g., marketing and packaging aesthetics [20].

Our goal is to set TRIZ suggestions forcing problem solvers to take into account environmental impacts.

\section{Proposal}

This section presents a tool for the development of green products. During design phase, each designer is supposed to follow a list of guidelines and accordingly modify the existing product to make it more environmentally friendly. The crucial point is to exploit problem solving strategies as a framework for eco-guidelines that guide the user to make product development, taking into account first of all sustainability objectives. It is important to understand that problem-solving tools are not easy to learn, so a strong simplification is needed to guide non-experts. Unlike a structured problem-solving method that involves a preliminary phase of understanding and modeling the problem, an eco-guideline acts exclusively as an inventive trigger. Therefore, it must be both simple to understand and effective.

\subsection{Guidelines Background}

This tool is derived from insights gained from the author's problem-solving experience both in the design and teaching areas, and especially Ecodesign experience with students and in real case studies.

The constant goal in these years has been to bring the complexity of problem-solving techniques into a user-friendly tool aimed at Ecodesign. To do this, we have worked on the mechanisms of activation of creativity that are typical of the TRIZ methodology, trying to translate it into guidelines bypassing every step of problem definition. We also tried to orient the inventive triggers towards a very focused target through the study of a rigorous ontology.

The guidelines proposed in this paper are the latest evolution of this long preparatory work. In a previous work, i.e., [16], the authors proposed a set of 300 Eco-guidelines (ITree), always based on TRIZ. The experience gained by applying ITree in the numerous applications in different industrial contexts, has been fundamental to confirm that this direction was promising but also that, unfortunately, problem-solving methods support users in inventing good but not necessarily greener solutions. The new set of guidelines, proposed in this paper, is the result of an attempt to rewrite problem-solving strategies confined to the environmental sphere and a simplification effort that has led to a drastic reduction in the number of guidelines.

The engine that resides within each guideline is the customization of a set of tools that are typical of the TRIZ methodology. Almost all suggestions are based on TRIZ tools: Inventive Principles, Separation Principles, Laws of Technical Systems of Evolution, Evolution Trends, and Functional 
Analysis-based Trimming. However, TRIZ is not a method born to do Ecodesign and, therefore, there has been a long work of selection and adaptation of individual instruments [35]. Only those instruments leading to solutions with less waste of resources have been chosen.

Resources play a key role in TRIZ. They are everything that remain idle in the technical system and its environment. Focusing on them, we exploit the energy resources and materials from the environment (inside or outside the productive plant), or waste (circular economy) to achieve a certain function. You can also use negative effects (e.g., Vibrations, resonance), changing unwanted functions to useful produce functions.

All TRIZ based suggestions aim to reduce material, energy, time, space resources required by the system, and identify and exploit the available (and unexploited) internal resources and discover external resources from the product environment.

The list of problem-solving-based suggestions, integrated in the proposed set of guidelines, is indicated in the Table 1.

Table 1. List of generic suggestions strategies.

\begin{tabular}{ccc}
\hline 1. Switch to super system & 6. Change the state of aggregation & 11. Dynamics \\
2. Trimming & 7. Local quality & 12 The Other Way Around \\
3. Dematerialization/ideality & 8. Substitute & 13. Taking out \\
4. Merging & 9. Segmentation of the & 14. Increase control \\
5. Redesign the internal structure & parts/components & 15. Recycle/Reuse \\
& 10. Design for Assembly & 16. Optimize \\
\hline
\end{tabular}

In the following sub-paragraphs, all the TRIZ instruments used in our Eco-guidelines are presented by a brief introduction and an explanation of the limits of validity, within which the way each application can produce a positive effect on reducing environmental impact. Except for the strategy \#8-Substitution, all strategies coming from the list of Table 1 come directly from TRIZ.

\subsubsection{Switch to Super System}

According to TRIZ Law \#6, during its evolution, when a technical system exhausts the possibilities of further significant improvement, it is included in a super-system as one of its parts. As a result, a new development of the system becomes possible. From an environmental point of view, the product reaches the minimum consumption of its energy resources, drastically reducing its environmental impact. The use of external resources usually does not contribute to increasing the impact as it concerns resources already present in the environment, and not yet exploited.

\subsubsection{Trimming}

Trimming is a good technique for making greener products. It consists of making a product constituted by fewer parts, with positive consequences on many aspects of the product life cycle, from the management of warehouse orders, storage, transport, as well as on reducing the mass. In order to achieve the maximum environmental benefits, it is preferable to start by eliminating those pieces having the highest impact on the environment. When a component is deleted from the system, it is better to try to exploit the resources already available in the super-system to replace its useful function.

\subsubsection{Dematerialization/Ideality}

According to TRIZ, the dematerialization of a product coincides with its Ideality. The TRIZ Ideal Product is that which does not exist while continuing to perform the function for which it was conceived. In this way, the product is not associated with any energy flow, material, packaging, etc., and cannot produce environmental impacts. It consists in eliminating all useless product components, reducing toward zero auxiliary materials, consumables, or eliminating the distance. The ideal lawnmower coincides, for example, with a lawn made of dwarf grass or grass inhibited in its growth so that it no longer needs to be cut. 


\subsubsection{Merging}

In the case of manufacturing processes, Merging suggests making operations contiguous or parallel, bringing them together in time. The combination of the processes brings benefits by eliminating the impacts associated with the internal transport and/or packaging of the material, eliminating the problems of repositioning the piece, as well as offering the synergies of several machines that share the same energy and control sources.

\subsubsection{Redesign the Internal Structure by Porosity}

Generally, in order to increase the mechanical strength of an object, the thicknesses are increased, or the materials are substituted with greater density, which irredeemably contribute to an increased object mass. In this case, instead to increase the performances by reducing the mass, the goal is acting on the topology or on the distribution of the masses within the volume of the object, arranging the mass only where it is needed and eliminating the portions which have no functional characteristics. A good trigger to help the designer in this task is to introduce TRIZ Principle \#31 "Porous materials", which involves making an object porous or adding porous elements. If already porous, you use the pores to introduce a useful substance or function into the object. Structural optimizer tools can be used to improve mass reduction, too.

\subsubsection{Change the State of Aggregation}

TRIZ Principle \#35 "Parameter change" entails changing an object's physical state to a gas, liquid, or solid; changing pressure or other physical parameters; changing the concentration or consistency; changing the degree of flexibility; or changing the temperature. TRIZ Principle \#36 "Phase transition" is the use of volume or other physical properties. The solutions working on the change in the physical state of the aggregation of a product provide results that are very appealing but not necessarily greener, e.g., a solid fuel is less explosive, but it is not more sustainable than other fuels. In order to achieve environmental benefits, it is advised to try its application on products where the transportation has a great incidence, e.g., the gases that, in liquid state, occupy less volume and all types of liquids in a freeze-dried form. The benefits of the change of state can be amplified by taking advantage of the temporary properties emerging during the phase transition. For instance, water expansion during freezing is a property known from thousands of years in mines, where large stones are placed within water cavities and are broken by ice expansion.

\subsubsection{Local Quality}

TRIZ Principle \#3 "Local quality" is used for reducing mental inertia when considering space and materials too homogeneous and continuous. It suggests to "Change an object's structure from uniform to non-uniform, make each part of an object function in conditions most suitable for its operation, and make each part of an object fulfill a different and useful function". We can say that, from the Ecodesign point of view, this principle tends to optimize the processes and, therefore, to reduce the energy and mass impacts. With the same principle we tend to conceive multi-function objects for exploiting synergies among functions.

\subsubsection{Substitute}

Substitute a material or an energy flow or changing a transport mean with a lower environmental impact. The application of this strategy has its maximum effectiveness if integrated with a library of materials and related environmental impacts.

\subsubsection{Segmentation of the Parts/Components}

TRIZ Principle \#1 "Segmentation" is the key principle to make the system work only where needed (only in the Operative Zone). Segmentation entails dividing a system or object into independent parts 
or components (disassembly) and recombine them in a more suitable way for the purposes to achieve (e.g., transport separately single parts). For example, use two small motors instead a big one to better optimize performance and exhaust gases. This principle does not guarantee greener results and must always be verified from an LCA (Life Cycle Assessment) point of view.

\subsubsection{Design for Assembly}

Design for assembly (DFA) is a process whereby products are designed with ease of assembly in mind. If a product contains fewer parts it will take less time and energy to assemble, thereby reducing assembly impacts. In addition, if the parts are provided with features which make it easier to grasp, move, orient and insert, this will also reduce assembly time, energy and costs.

\subsubsection{Dynamics}

TRIZ Principle \#15 "Dynamics" is the key principle to make the system work only when needed (Operative Time) and always in an optimal way. Dynamics allows (or design) the characteristics of an object, external environment, or process to change to be optimal or to find an optimal operating condition. If an object (or process) is rigid or inflexible, make it movable or adaptive. Any increase in efficiency has a positive effect on energy savings by the machine or the manufacturing process.

\subsubsection{The Other Way Around}

TRIZ Principle \#13 "The Other Way Around" is simply reversing the normal procedure or process. According to it, invert the action(s) used to solve the problem (e.g., instead of cooling an object, heat it); make the movable parts of the entity fixed, and the fixed parts movable; turn the entity 'upside down'; nest objects inside others; and exploit other dimensions. This principle can be a very useful for finding better solutions, but it does not guarantee greener results that must be always verified from an LCA point of view.

\subsubsection{Taking out}

TRIZ Principle \#2 "Taking out" means to separate an interfering part or property from an object, or single out the only necessary part (or property) of an object. It forces users to use only what is needed, thus reducing the environmental impacts.

\subsubsection{Increase Control}

According with the third law of system evolution, all technical systems can be represented at least by the engine, the transmission, the working unit and the control elements for each of them. If one of these control elements is lacking, try to introduce it, while if it is insufficient try to improve it. More control means bigger efficiency and energy reduction.

\subsubsection{Recycle/Reuse}

Recycle/Reuse is part of the "Switch to super system" TRIZ suggestion. However, it appears in this form in the end of use phase guidelines. Recycling allows the elimination of disposal impact, while reusing helps to reduce impacts produced by the disassembly and the recycle operation, in addition to those deriving from the production of new products.

\subsubsection{Optimize}

Optimization is present in many inventive principles even if, alone, is not a classical TRIZ approach; it can be useful for reducing impacts every time helps user to increase efficiency, reduce mass and eliminate unnecessary parts. It is introduced into guidelines by adapting technical suggestions to the specific context; i.e., during manufacturing processes, reduce the casting channels during the melting, and eliminate additive manufacturing supports for reducing wastes. Furthermore, reduce machining 
operations for cutting shavings, limit the surface finishing treatment areas for saving energy, and improve die-castings to reduce defects, conceive the piece so that it is more resistant for the subsequent assembly phases, etc.

Each of these strategies must be able to work regardless of the user's knowledge of TRIZ tools.

The next section presents how each suggestion is combined within the guideline structure and how it is surrounded by other modules that help the user to contextualize it and to suggest where and when to apply it.

\subsection{Guidelines Structure}

TRIZ-based guidelines are reformulated through a rigid structure including four main parts. The WHEN part describes the main phases of product lifecycle within the guidelines act (pre-manufacturing PM, manufacturing M, use U, end-of-life EoL). The ACTION part indicates the target to be improved. It callbacks a list of objects onto which the user applies high-level eco-strategies. The actions selected in our list are normally used in most of the methods of Ecodesign, usually even without specifying which elements they refer to. The WHAT part completes Actions, clarifying the specific purpose of the guideline. The HOW part is conceived for explaining the modalities to achieve the specific purpose. It introduces a deeper level of description based on the problem-solving triggers.

To facilitate their comprehension, they are not numbered but have a speaking code according this format: "(WHEN) you want to intervene, (ACT) on components (WHAT), by doing something (HOW) and using one resource (from the Resource list) to find alternatives and assess environmental impacts". The name of each guideline is comprised of three parts: WHEN_code (PM-M-U-Eol), ACTION_code (Eliminate, Reduce Mass, Reduce Distance, Reduce Quantity, etc.) and WHAT_code (Energy, Aux.Materials, Packaging, External Logistic, etc.).

More in detail, the HOW part contains two levels of description called Generic suggestions and Resource list. A list of examples completes this part.

In the How part, TRIZ-based suggestions, from Table 1, are made explicit by means of a description in natural language, and contextualized in accordance with WHEN, ACTION and WHAT triads.

In some cases, a further explanation in the form of a list can be added: list of structural resources classified according to the state of substance, transformable substance and other substances groups; list of physical fields divided into Mechanical, Acoustic, Thermal, Chemical, Electric, Magnetic, Intermolecular, Biological areas; and list of combination between physical effects (e.g., Magnus effect) and ultimate functions (e.g., move a ship). In order to exploit a larger set of these combinations, guidelines can be integrated with a home-built software called TechFinder [36].

Examples introduce real solutions and case studies for better understanding how guidelines can be applied. They have been identified in scientific publications, technical catalogues, real case studies.

Figure 1 reports the parts constituting a single guideline.

a PROPOSED GUIDELINE is made by

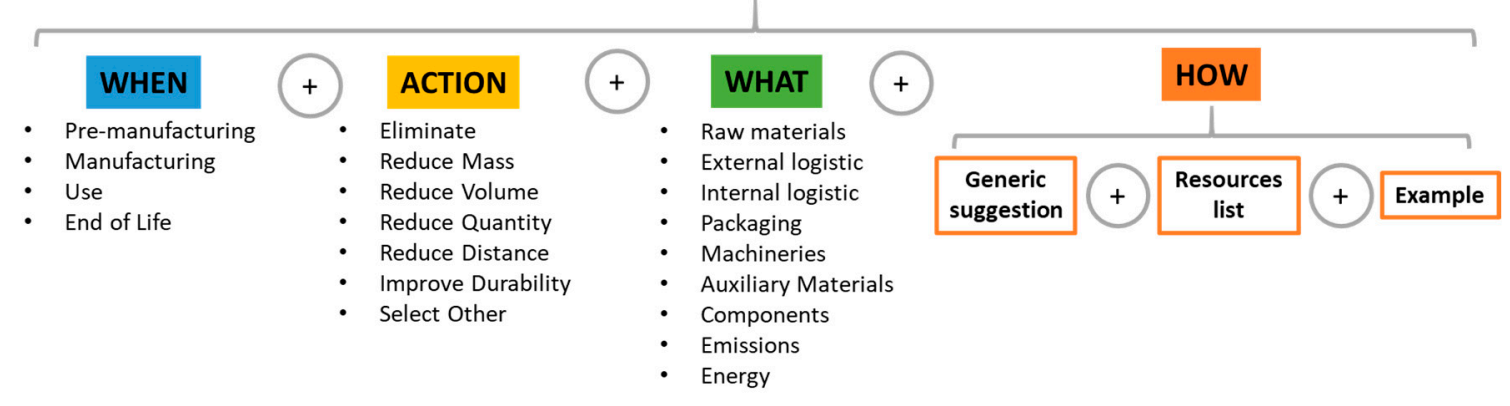

Figure 1. Main blocks constituting a guideline.

In Figure 2, the structure of a single guideline is presented by specifying its main constituting parts. 


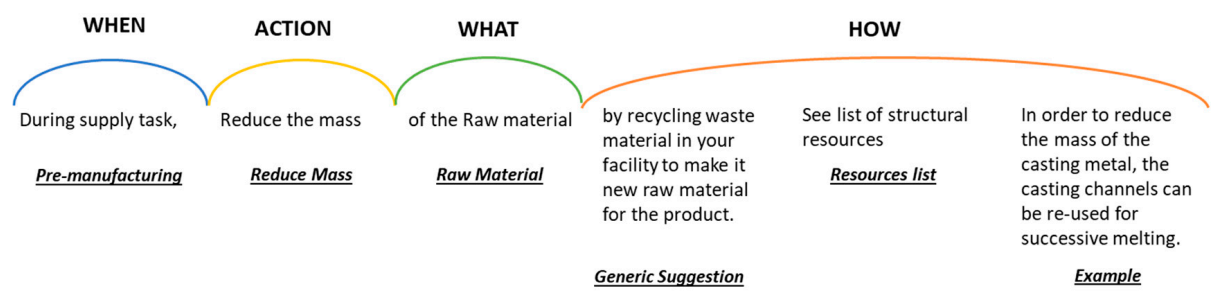

Figure 2. Example of a single guideline by highlighting the constituting parts.

\subsection{Guidelines Organization}

The guidelines are 59 in all, organized in four life cycle phases; each of these has a sub-branch in five or six actions, which in turn may contain several objects and for each of them, the available strategies are reported in terms of Generic suggestions and Resource list. The overall framework with which the guidelines were built is shown in Figure 3, along with all the used acronyms.

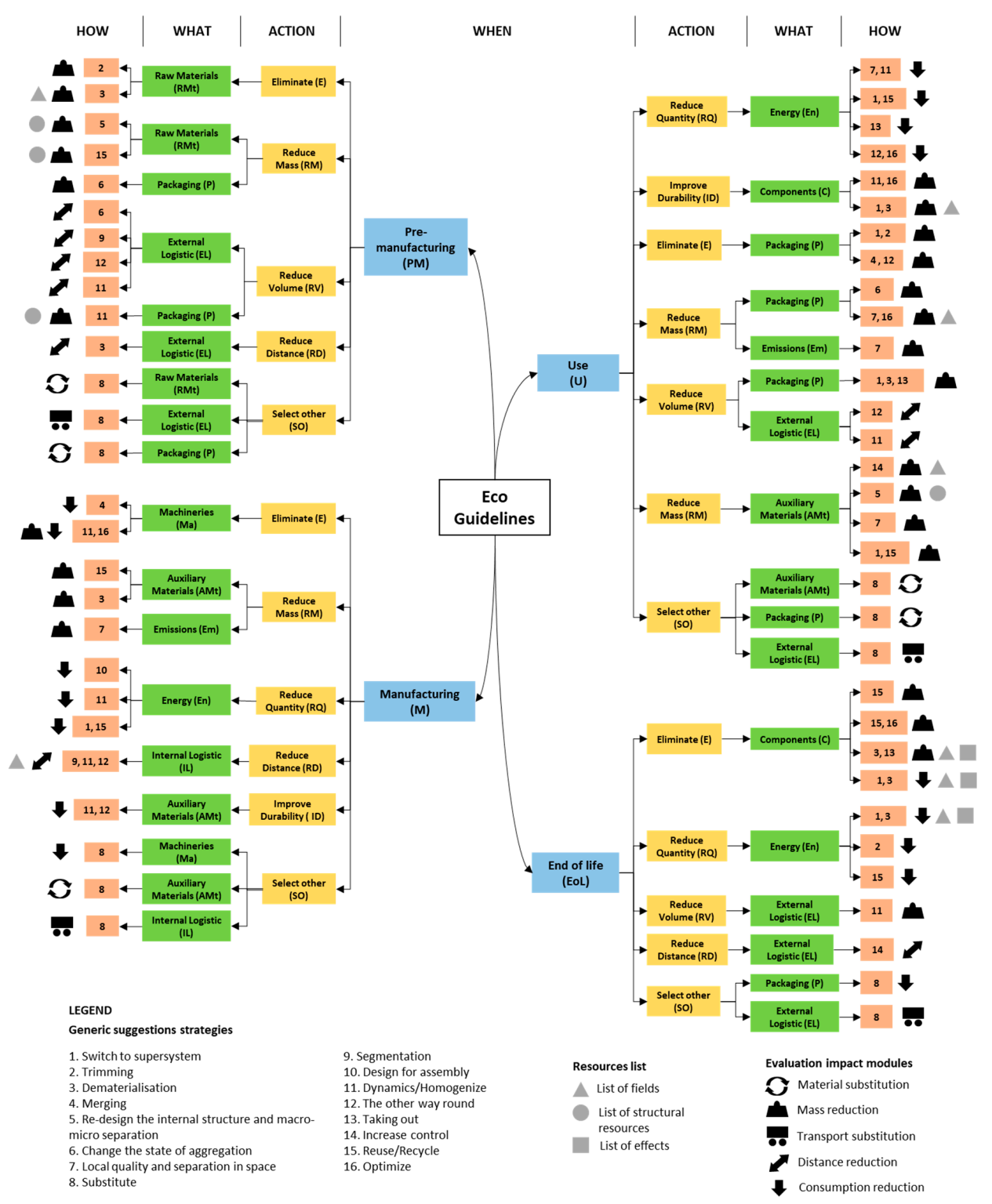

Figure 3. Guidelines map. A hierarchic organization divided into four levels of detail: level 1-WHEN, level 2-ACTION, level 3-WHAT and level 4-the HOW part containing the common problem-solving (PS) strategies used for the generic suggestions and resources list. 


\section{Guidelines Presentation}

The complete set of 59 guidelines are reported within a database, freely available at the following link: http://chsp.altervista.org/EcodesignMap/index.html.

They can be used randomly or as a check list. However, the recommended way to do this is downstream of an LCA where you can highlight the critical issues that need to be addressed. An LCA in fact allows us to circumscribe the intervention on a single component, highlights whether the problem is of an energy nature, or an excessive use of material rather than related to transport or packaging, and finally always identifies in which phase of the life cycle it manifests itself. The speaking code of our guidelines makes it easier to achieve only the guidelines that are compatible with this objective.

For the sake of brevity, only a narrow selection of the complete set of 59 guidelines is presented. In the following 16 sub-paragraphs, there is a guideline representative of a different TRIZ suggestion randomly chosen from those available in the guidelines database.

\subsection{M_RM_AMt-Reduce Mass Auxiliary Materials (Swith to Supersystem)}

During manufacturing, reduce the mass of auxiliary materials (i.e., consumables) by recycling them from inside or outside the productive plant, or by extending their operative life, with or without making changes to them.

- Make the manufacturing process more robust for tolerating the deterioration of the performances of the auxiliaries.

- Treat exhaust auxiliary materials by reinvigorate them (e.g., cleaning and filtration for oil, sharpening for tools).

Examples: recycling lubricating oil for reducing the global warming potential, cumulative energy demand, acidification and toxicity [37]. Regenerating tools in CNC stations and foundry molds for plastic or integrating inserts of a new material in limited parts.

\subsection{U_E_P-Eliminate Packaging (Trimming)}

During delivery phase, eliminate the (primary packaging) packaging, by demanding its role of protection and/or advertising (e.g., energy or nutrition labeling), directly to the product itself or to the secondary packaging that contains the primary packaging.

- Modify the product surface by reporting on it advertising or information (e.g., nutritional value).

- Eliminate part of the packaging by directly showing the contained product.

- Make minor improvements to the secondary packaging by making it suitable to contain the product (e.g., by making it waterproof for storing liquids).

Examples: reproducing the bio-label on the fruit peel trough laser marking. Showing the contained product as advertising for reducing the packaging mass. Directly filling the tanks of the printers instead of using cartridges.

\subsection{PM_E_RMt-Eliminate Raw Materials (Dematerialization/Ideality)}

During the design phase, design components using less or no material to deliver the same level of functionality by compensating their functions with a field (e.g., electromagnetic, light, laser).

Examples: in the smartphone, there are many different devices totally dematerialized (e.g., photo camera, radio, voice recorder, etc.) embedded within it. Paper [38] compared the environmental impacts of a single smartphone and 18 devices, by finding a reduction in power consumption (449 vs 5 Watts), embodied energy (1706 kWh vs $75 \mathrm{kWh}$ ), stand-by energy use (72 vs 2.5 Watts) and weight (26 vs $0.1 \mathrm{~kg})$. 


\subsection{M_E_Ma-Eliminate Machineries (Merging)}

During manufacturing, eliminate one or more machineries/manufacturing processes by merging them with others in order to perform multiple operations on the resulting work center, saving the overall energy.

- Reduce the movements of the semi-finished among the two machineries by ideally bringing them to zero if the two operations can be carried out by fixing the piece in the same position.

- Share the hardware, i.e., tools, consumables, sensors and their management/handling systems (e.g., lubricant pump), for both the operations.

- Merge the operations themselves by optimizing the sequence of operations to be performed according to the logic of the work center: e.g., the combination of cutting and punching for laser-punching machines.

Examples: in order to save oil and energy during frying, an American potato chips producer, instead of using the pressing machine and frying machine, eliminated the second one by adding the vegetal oil within the pressing machine for directly frying the potatoes during the pressing. The introduction of hybrid manufacturing allowed both chip removal and additive manufacturing within the same machine, through a more efficient use of the resources available, machines and materials [39].

\subsection{PM_RM_RMt-Reduce Mass Raw Materials (Re-design Internal Structure)}

During design phase, reduce the mass of the raw material, increasing its internal porosity or arranging the mass only where it is needed and eliminating the portions which has no functional characteristics. Try to optimize internal structures without compromising the performance (stiffness, thermal or electrical conductivity). Use the list of resources from the "Resources List" module.

- List of structural resources.

Examples: [40] collected and compared a multitude of paper packaging made by different lightweight structures (e.g., wavy, porous, corrugated, expanded, perforated) in terms of sustainability. A multi-national packaging reduced the weight of their packaging up to $70 \%$ by realizing an internal honeycomb structure.

\subsection{PM_RM_RMt-Reduce Mass Raw Materials (Change the State of Aggregation)}

During the supply phase, reduce the mass of the packaging of the raw material, by changing the state of aggregation of the raw material in order to make it more resistant to be carried with a lighter packaging.

Examples: transporting milk in powdered form from farm to factory by using simple plastic sachets instead of the conventional metallic bins. Additionally, producers of other foodstuffs, e.g., dehydrated fruit, fish, e.g., exploit the same strategy.

\subsection{U_RM_AMt-Reduce Mass Auxiliary Materials (Local Quality)}

During product use, reduce the mass of auxiliary materials by rationalizing and controlling their use only where and when are specifically required.

- $\quad$ Reduce the thickness of the film of lubricant (especially where it is not needed).

- Confine the presence of lubricant or cooling only in the most critical zones (e.g., where the temperatures or the frictions are higher).

- Combine lubricants or fuels with different qualities: use the better one only when the product is working with the full performances. 
Examples: redesigning the surface roughness for optimizing the adherence of the film lubricant and reducing its thickness [41]. Optimizing the shape of the creeping gaskets for confining a small quantity of lubricant (up to $25 \%$ less according to a North European company) only where friction is greater.

\subsection{M_SO_IL-Select Other Internal Logistic (Substitute)}

During manufacturing, select other transportation means for internal logistic, by privileging those more sustainable during the lifecycle and, in particular, those requiring less energy consumption and better energy sources to move the given load across a certain distance.

Example: in order to increase the efficiency of internal logistic and reducing the impacts, in 2016, a swiss brewery substituted all 217 of its diesel forklifts with electric models which are $30 \%$ more efficient, saving a total amount of 100,000 L of fuel, or about 260 tons of $\mathrm{CO}_{2}$ emissions.

\subsection{PM_RV_EL-Reduce Volume External Logistic (Segmentation of the Parts/Components)}

During supply phase, reduce the volume of the external logistic, optimizing the disposition inside the transportation mean, by physically dividing the raw materials in pieces and then recombining them in a more suitable way during the transportation.

Examples: compressing data by packing them during transmission and unpacking them after the reception to save the total amount of shared data and, therefore, the mass of the transmission cables. Removing tree trunks from the branches and cut them into various pieces during transport.

\subsection{M_RQ_En-Reduce Quantity of Energy (Design for Assembly)}

During manufacturing, reduce the required energy by optimizing the design for assembly of the product (i.e., kind of involved parts and shapes).

- Redesign the geometry my making it more accessible for automatic interventions: eliminate undercuts and reduce displacements of robots' arms and auxiliary materials.

- Use asymmetrical parts for facilitating the correct orientation and position of the piece during assembly in order to reduce its displacements.

- Introduce quick joints and standard parts for reducing the number of assembly tools substitutions.

Examples: a Chinese manufacturer introduced a standard architecture for electronic products by reducing the number of components and designing the part orientation. [42] presented a novel methodology for supporting product re-design through the reduction of the number of its parts and evaluating the environmental impact.

\subsection{M_RQ_En-Reduce Quantity of Energy (Dynamics)}

During manufacturing, reduce the required energy by optimizing the temporal dynamic of the manufacturing process (machineries and internal logistic) in relation to the production rate.

- Move them from continuous to discontinuous operation (start and stop).

- Optimize their speed rate (i.e., reduce when possible) by planning through a dedicated software.

- Optimize their processed and carried load.

Examples: developing algorithms for investigating the optimal cutting conditions in relation to energy consumption and waste management [43], or the lubricant consumption (e.g., [44]). Investigating the most suitable production route in additive manufacturing for minimizing energy consumption [45]. One could press a nail into the wood with a finger for $10 \mathrm{~s}$ without effect or exert the same amount of energy and drive the nail instantaneously into the wood with a single strike of a hammer. Pulsed ultraviolet radiation, like the hammer, delivers light at high peak power for deep penetration. Pulsed UV systems consume up to $80 \%$ less energy than continuous UV cycle. 


\subsection{PM_RV_EL-Reduce Volume External Logistic (The Other Way Around)}

During the supply phase, reduce the volume of the external logistic, optimizing their physical disposition inside the transportation mean using all dimensions and empty spaces.

- Move in two- or three-dimensional space (e.g., Tetris game).

- Use a multi-story arrangement of objects instead of a single-story arrangement.

- Tilt or re-orient the object, lay it on its side (upside down).

- Use "another side" of a given area.

- Exploit all empty spaces (i.e., Matryoshka) or less conventional directions (moving out from horizontal/vertical plane towards diagonal directions) or using 3D placement.

Examples: low-diameter sheet coils be placed inside large diameter coils during transport. Truck loading optimization for paper rolls, pallets, skids and boxes via trailers, containers and railcars, made by commercial software.

\subsection{EoL_E_C-Eliminate Components (Taking out)}

For improving the end of life, eliminate the components (i.e., hazardous materials) that reduce the reuse, the recyclability or the disposal of the product by removing them from the product with less energy.

- Try to exploit:

- Fields and forces from the environment (e.g., gravity, geodetic share of water).

- Heating coming from sun or subsoil (e.g., drying).

- Physical effect requiring small energy to be exploited (e.g., fluid pression, centrifugal force, vibrations).

- List of fields and forces; list of physical effects.

Examples: eliminating low-content impurities from Aluminum solidification by exploiting centrifugal force in rotative furnaces [46]. Biodrying, biostabilization, thermal drying and solar drying for de-humidifying urban wastes before incinerators [47].

\subsection{U_RM_AMt-Reduce Mass Auxiliary Materials (Increase Control)}

During product use, reduce the mass of auxiliary materials, by introducing a field acting as a control for monitoring the environmental conditions (e.g., weather conditions, air humidity), the product (e.g., wear status) and the conditions of the same auxiliary materials.

- $\quad$ List of Fields and Forces.

Examples: irrigation systems connected to the web (Internet of Things) for saving waters according to weather forecasting. Photocells on the taps in public toilets to detect the user presence.

\subsection{EoL_E_C-Eliminate Components (Recycle/Reuse)}

For improving the end of life, eliminate the product to be disposed by reusing it or its components as they are or after reparation for performing the same function or for other uses inside or outside the operating context, or by maintaining them as spare parts for other systems (see circular economy).

- Rethink the use of the product by tolerating a decreasing in the performances.

- Repair/regenerate the product by making it able to perform the same functionalities through design for repairability and design for update.

- Do not dispose the product only to the realization of those functionalities have not been compromised by the wear of time. 
Examples: containers, newsstands, pallets and bins used in architectural buildings and furnishing. Savannah College of Art and Design designed an easily repairable and upgradable microwave containing slots for updates, easily replaceable parts, also not original or from other models. Former Italian high-speed trains used in regional lines. Ship restaurant moored at the port.

\subsection{M_E_Ma-Eliminate Machineries (Optimize)}

During manufacturing, eliminate one or more machineries/manufacturing processes by optimizing the shape of the semi-finished, thinking not only about how it should be at the end of the process but also in relation to the sequence of all its processing phases (construction of the piece, finishing and assembly).

Examples: optimizing the topology design of the components realized through additive manufacturing allowed a remarkable reduction of the impacts compared to CNC milling [48]. Optimizing the speed of injection of the liquid material inside the molds for reducing the connection radii and the voids and the volumes of the sprues [49]. Density-based topology (i.e., Bridging topology) optimization for eliminating the supports in additive manufacturing [50].

\section{Exemplary Case Study}

In order to show how the guidelines can be applied, this section proposes a case study dealing with the redesign of a mechanical ball valve for fluids. It is a mechanical device that allows you to close and open a mobile bulkhead with respect to the valve body, moving it by means of a lever that can be locked in different positions. The main environmental criticalities of this object lie in the materials used, i.e., the stainless steel used for most of the components and the rubbers for the gaskets, which have a significant impact. A schematic representation of this device and ints main components is shown in Figure 4.

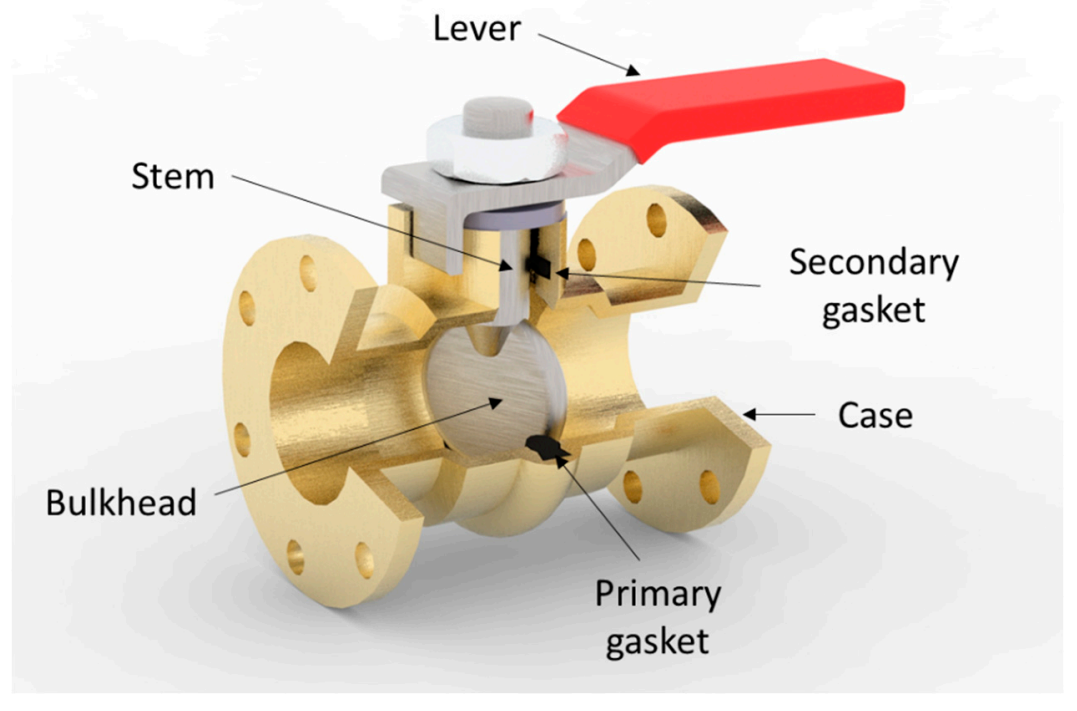

Figure 4. Representation of a common mechanic ball valve.

In the following, some solutions emerged by the applications of some guidelines are reported.

\subsection{M_RM_AMt-Reduce Mass Auxiliary Materials (Swith to supersystem)}

The use of biodegradable plastic materials for the construction of the valve allows to delegate the disposal function to the environment at the storage site. Among them, Polylactic Acid (PLA) is frequently exploited in additive manufacturing to replace traditional polymers, ensuring a lower carbon footprint, mainly due to biodegradability and similar characteristics in terms of mechanical 
strength and reproducibility. Some manufacturers already use the additive with PLA to produce valves (see Figure 5a).

\subsection{U_E_P-Eliminate Packaging (Trimming)}

Since the valve is a massive and more robust than paper and cardboard, the primary packaging is generally used only as support for gathering information (e.g., bar code, technical features). It could be totally eliminated by moving the information directly on the surface of the valve (i.e., through laser marking) and/or the surface of new disposable caps made of recyclable material, which also prevent the entry of dust into the valve case (see Figure $5 b$ ).

\subsection{PM_E_RMt-Eliminate Raw Materials (Dematerialization, Ideality)}

This guideline suggests eliminating some components of the valve by delegating their action to some field or force. For example, the magnetic field is used in active solenoid valve (e.g., [51]) in order to open and close the valve by a vertical translation of the mobile bulkhead. This solution comprises a solenoid which generates a magnetic field when it is passed through by the current. The latter attracts or repels, depending on the direction of the current, a metal rod that slides vertically and to which the movable bulkhead is fixed (see Figure 5c). With very low power consumption, this solution eliminates the lever and operating mechanism of the mobile bulkhead.

Another idea is to eliminate the internal components redesigning the case of the valve with deformable elements which achieve closure without the mobile bulkhead and its operating mechanism. The deformable case can be mechanically compressed from the outside by a piston or by rollers similar to a mill or attracted by a magnetic field exploiting material for the case with strong magnetostriction (see Figure 5d).

\subsection{M_E_Ma-Eliminate Machineries (Merging)}

In mono- and multi-material valves made by additive manufacturing, the movable parts can be directly printed within the case depending on the geometries, especially in small applications and in order to avoid some assembly operations (e.g., [52]).

\subsection{PM_RM_RMt-Reduce Mass Raw Materials (Re-design Internal Structure)}

Different cases of valves on the market are made by additive manufacturing, saving the quantity of material used by appropriately acting on the infilling, creating an internal porous or honeycomb structure (see Figure 5e).

\subsection{PM_RM_RMt-Reduce Mass Packaging (Change the State of Aggregation)}

Although in this case study, the valve packaging was not considered, with an easy analogy we can think at the cage and the bulkhead as the envelope of the fluid passing through the valve, which can be solidified in order to stop the flow instead of the bulkhead.

By freezing the fluid within the valve, the ice barrier that is created can block it even without the bulkhead, which can then be removed together with the lever and the actuation mechanism and replaced by Peltier cells or by using cold environment when present. Energy consumption for creating a cold environment is as low as the flow rate is small. (see Figure 5f).

The same purpose could also be accomplished by using magnetorheological fluids which increase their viscosity when subjected to a magnetic field. Where it is possible to insert this type of substance into the fluid (e.g., closed circuits of car brake systems) they can block the flow without the need for a bulkhead. For small thickness valves, their activation could be guaranteed by a low current absorption electromagnet (see Figure 5g). 


\subsection{U_RM_AMt-Reduce Mass Auxiliary Materials (Local Quality)}

This guideline leads us to think about the local characteristics of the components, for example, the internal walls of the valve and their interaction with the fluid (i.e., hardness, roughness, friction, adhesion, hydrophobia, capillarity, cavitation, emulsion). The capillary valve (e.g., [53]), typically used in very small ducts, exploits the capillary forces between the walls of the casing and the fluid that passes through it to block it. This effect can be accentuated by coating the inside of the case with a hydrophobic material, especially when the diameter of the duct increases or to increase the maximum operating pressure. Their operating principle allows to eliminate moving parts, i.e., the bulkhead, lever and actuation mechanism (see Figure 5h).

\subsection{M_SO_IL-Select Other Internal Logistic (Substitute)}

Similarly to the replacement of the transportation mean with a less impacting one, also substituing the constituting materials can bring benefits on the environment. PLA, previously described (see Figure $5 a$ ), is a more sustainable matarial to be use for realizing the valve.

\subsection{PM_RV_EL-Reduce Volume External Logistic (Segmentation of the Parts/Components)}

In order to minimize the dimensions during transport, the valve lever, which is already removable in most cases, could be inserted within the cavity of the case during transport and mounted before use, and it can composed of several parts to further facilitate these operations. In addition, some commercial valves are transversally divided into two or three parts and assembled by means of ring nuts and gaskets. This option considerably reduces the volume of each valve during transport. On the other hand, however, this segmentation introduces new components such as screws; it is worth segmenting the valve only in those cases where transport is the most impacting aspect of the life cycle.

\subsection{M_RQ_En-Reduce Quantity of Energy (Design for Assembly)}

In order to eliminate the screws, valves made up of several parts joined with screw joints (see example in Section 5.9) could be also assembled using snap joints as well known in plastic valves for gardening (see Figure 5i).

\subsection{M_RQ_En-Reduce Quantity of Energy (Dynamics)}

In order to dynamically adapt the valve to the operating rhythms of the external environment, its internal diameter can change diameter according to the pressure of the fluid passing through it, until it closes completely, blocking the passage without the need for the mobile bulkhead and the lever. One possibility is to use collapsible case walls, like a flutter valve (see Figure 5j), flexible plates or compliant mechanism arranged within the internal duct of the case (e.g., [54]) (see Figure 5k).

\subsection{PM_RV_EL-Reduce Volume External Logistic (The Other Way Around)}

In order to reduce the space during transport, the valve lever can be made by means of a movable stem which, in addition to rotating, can also translate longitudinally with respect to the valve stem, so as to reduce the cantilever arm during transport and increase it for use. This option has been used by several manufacturers to optimize the arrangement of the valves inside the cardboard boxes (see Figure 51).

\subsection{EoL_E_C-Eliminate Components (Taking out)}

In order to easily remove the plastic coating from the metal lever of the valve during end-of-life, electrostatic rotative separators are estimated to be the most efficient machineries from the point of view of energy consumption. They combine the separation by friction due the sliding of the parts to be separated against the internal walls of a rotating drum exploiting centrifugal force with the magnetic separation generated by a localized high-voltage field. 


\subsection{U_RM_AMt-Reduce Mass Auxiliary Materials (Increase Control)}

Monitoring the valve to check when it is not completely closed could avoid material loss. The closure check can be performed by introducing various auxiliary materials into the valve that act as indicators: flexible metal sheets, fluids with different densities, pipes (e.g., Pitot pipe), etc. The real-time measurement of the electrical resistance of a circuit which includes the valve casing and the mobile bulkhead, which act as two ends of a switch, allows to evaluate the closure. The required electrical circuit can be created by drowning a very thin aluminum wire inside the two components and using a trivial system for reading the electrical resistance (see Figure $5 \mathrm{~m}$ ).

\subsection{EoL_E_C-Eliminate Components (Recycle/Reuse)}

A valve that uses the same material for all its components facilitates recyclability. Those completely made of plastic are an example, even if the use of plastic springs could be a problem for those models that require them, due to their performance and reliability. However, lately, many manufacturers have been making polycarbonate, polyacetal and polyurethane springs able to fully comply with the regulations for many types of valves.

In addition, since the lever is the crudest part of the system, it can also derive from a processing waste of any other company.

\subsection{M_E_Ma-Eliminate Machineries (Optimize)}

This guideline leads to think about list of the constructive operations to realize the valve in order to eliminate any undercuts and redesign the connection by eliminating the threads.

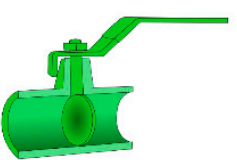

(a)

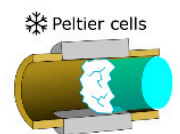

(f)

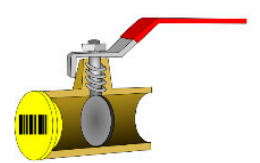

(b)

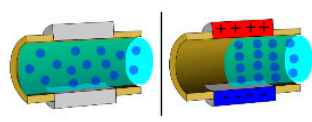

(g)

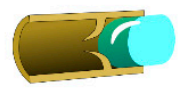

(k)

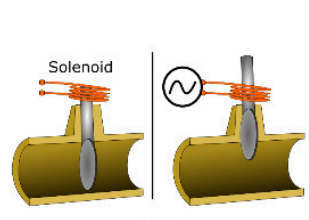

(c)

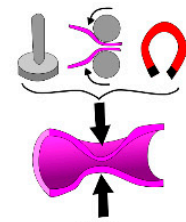

(d)

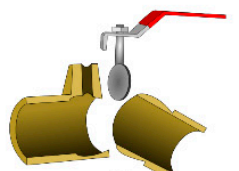

(i)

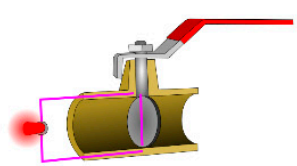

(m)

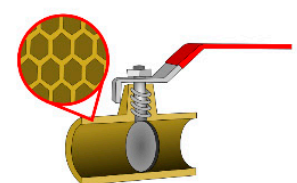

(e)

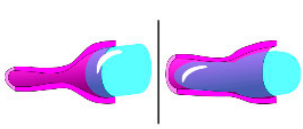

(j)

Figure 5. Schematic representation of some solutions for improving the sustainability of a ball valve, obtained through the eco-guidelines $(\mathbf{a}-\mathbf{m})$.

\section{Guidelines Validation}

In order to validate the proposed method, a test campaign with students was carried out, using real industrial case studies and evaluating both the solutions proposed by the students and the outcome of the questionnaires proposed to them.

The aim of this test is to evaluate the following two hypotheses related to the Eco-guidelines.

HP.1: The method leads the users to propose better solutions.

HP.2: The guidelines are comprehensible and useful.

With the first hypothesis we want to evaluate if the solutions proposed through the application of the method are better of what we would have had without the method in terms of numerosity and 
quality or achieving better environmental performances. Other common indicators, such as novelty or creativity were not considered in this first phase of evaluation.

While, with the second hypothesis, we want to comprehend if all the constituting parts of the guidelines are clearly comprehensible and which parts must be improved yet.

\subsection{Cases Studies}

In order to investigate the efficacy of the method in different domains of application, some case studies were considered.

The first one concerns a shaving foam aerosol valve. It is a device that regulates the dosage of the gas contained in the can by manually operating a one-button dispenser that automatically returns to the initial position through a spring. It consists of several pieces (e.g., button, stem, cover, spring) made of plastic, stainless steel, rubber, aluminum. The main environmental criticalities are the materials and the energy required during assembly, which is considerable in relation to the huge overall number of valves produced.

The second one deals with the concerns the collection mechanism of a harvester machine. It consists of three main parts: the gathering head, the intermediate duct and the beater. The gathering head detaches the drums to be harvested and directs them through the intermediate duct, typically realized by a tubular shape with a rectangular section, to the internal part of the machine where the beater is positioned, or a rotating drum equipped with protrusions wrapped in by a stator, which causes the parts to disintegrate by friction. The main environmental criticalities of this system arise from the considerable masses of all the constituent components and the high energy consumption required to operate the moving parts of the harvester head and the beater.

\subsection{Test Participants: Background and Expertise}

The validation of the guidelines in this version was conducted in two classes of students with different specializations and both belonging to the engineering courses of the University of Bergamo. The first, named "Product and Process Innovation (PPI)", is a compulsory course for the master's degree in mechanical engineering. It aims at providing a deeper knowledge about systematic innovation, especially TRIZ theory [21]. The basic idea is to provide the students with a structured approach for analyzing product and processes and solve technical problems. On average, the class is composed of 45-50 students and the course counts for eight ECTS (European Credit Transfer and Accumulation System) and it is structured in $80 \mathrm{~h}$; half of the course duration is dedicated to practical exercises. No specific modules for Ecodesign and Life Cycle Assessment are provided by the course. The latter, named "Methods and tools for product lifecycle" (i.e., PLM-Product Life-cycle Management), is an elective course for the master's degree in Mechanical Engineering and Management Engineering. It aims at providing an overview of computer-aided tools (e.g., CAD, CAE, PDM, ERP) to support the product development process and methodologies (e.g., BPR, DfX and also at least $10 \mathrm{~h}$ about LCA) to manage the whole product lifecycle, from the conception to the disposal. On average, the class is composed of 50 students and the course consists of six ECTS structured in $60 \mathrm{~h}$. Half of the course duration is dedicated to practical exercises, also involving the application of eco-assessment and Ecodesign methods. Usually, only $50 \%$ of the course students are involved in this activity, which they can carry out individually or in groups.

In this test we considered only a limited number of results, selecting only the most recent ones of the students who have applied the guidelines exactly in the version presented in this article. Overall, the considered students are 72, of which 40 from PPI and 32 from the PLM group.

\subsection{Test Execution: Available Time, Materials and Proposed Outputs}

During the test, each student was provided with only one of the two case studies through a random assignment. Then, the 20 PPI and the 16 PLM students of each case study have been further 
divided in half into two sub-groups: the test group and the control group, which include 10 PPI and eight PLM students each.

The case study was provided to all students by highlighting the critical environmental problems, previously identified through the Life Cycle Assessment analyses, to be addressed through the application of the guidelines in a rather evident way. The guidelines were provided to all students through the web portal. Test group students could fully access the guidelines, while the modules containing their HOW parts were deactivated for the control group. This application method is used to simulate the generic Ecodesign methods that simply provide indications on which entity to intervene in the form of triggers, as in the WHEN, ACTION and WHAT parts. No prior guidance on how to read or interpret eco-guidelines has been provided to students, in order not to compromise the level of understanding of their description, which is being investigated in this test. In addition, depending on the case study, not all 59 guidelines were provided, but only those related to the most critical components and life cycle phases according to the eco-assessment analysis. Such a selection allowed us to verify the potential and efficacy of the proposed method on students with different background and without providing any introduction. Both groups were asked to apply the guidelines in a simplified way, with a maximum time available of no more than half a day.

Each student presented the solutions within a PDF report and a questionnaire. For each solution in the report, the student indicated the goal highlighting the environmental improvement, a detailed description of the proposed solutions taking into account their shape, material and working principle together with a schematic sketch. The questionnaire contained direct questions in closed form dealing with how guidelines are presented, their comprehensibility and a self-evaluation in terms of quantity and quality of the identified solutions. It also ensured participants were able to leave comments.

\subsection{Evaluation Criteria}

Different criteria were used to evaluate the obtained results in order to verify the considered hypotheses. To assess HP.1, the provided solutions were evaluated, by considering only those ensuring the realization of the function and the main requirements. The numbers were evaluated by comparing the numbers of solutions provided by the test groups, vis-a-vis those of the control groups. The control groups could not access the full description of the 59 guidelines, but only WHEN, ACTION and WHAT parts. The quality of the solutions was instead assessed through a simplified Life Cycle Assessments, according to carbon footprint, water consumption and depletion of non-renewable resources, and counting only those solutions that lead to real environmental benefits that are clearly quantifiable. To assess HP.2, at present we have relied on user judgment, counting the answers to the questionnaire, dealing with the comprehensibility and usefulness of the different parts of the guidelines.

\subsection{Results and Discussion}

In this section, the results of the analysis are reported and discussed in referring to the two groups of students.

\subsubsection{Testing HP.1 Does the Method Lead the Users to Propose Better Solutions?}

Table 2 reports the results about the evaluation of the proposed solutions in terms of numerosity and quality in order to verify HP.1. Where numerosity expresses the average number of solutions proposed by each participant, while quality counts how many solutions from numerosity effectively reduces the environmental impacts. The results are divided according to PPI and PLM courses, test and control groups and the solved cases studies.

Based on the achieved outcomes and in relation to the limited number of participants, HP.1 is verified in all the considered configurations, i.e., students' groups and cases studies. The guidelines increased both the numerosity and the quality of the achieved solutions. The better results were achieved by PPI group for both the evaluation parameters, while PLM group obtained the widest advantages. 
Table 2. Results about the test of HP.1. numerosity and quality are expressed for each participant.

\begin{tabular}{cccccc}
\hline & & \multicolumn{2}{c}{ PPI Group } & \multicolumn{2}{c}{ PLM Group } \\
\cline { 3 - 6 } & & $\begin{array}{c}\text { Test } \\
\text { Group }\end{array}$ & $\begin{array}{c}\text { Control } \\
\text { Group }\end{array}$ & $\begin{array}{c}\text { Test } \\
\text { Group }\end{array}$ & $\begin{array}{c}\text { Control } \\
\text { Group }\end{array}$ \\
\hline Case study 1 & Participants & 10 & 10 & 8 & 8 \\
\hline & Numerosity & 4.3 & 2.5 & 2.3 & 1.5 \\
\hline Case study 2 & Quality & 3.9 & 1.8 & 1.9 & 0.6 \\
\hline & Quality/Numerosity & $91 \%$ & $72 \%$ & $83 \%$ & $40 \%$ \\
\hline & Participants & 10 & 10 & 8 & 8 \\
\hline & Numerosity & 3.9 & 2.6 & 3.3 & 1.6 \\
\hline & Quality & 3.6 & 2 & 2.3 & 0.9 \\
\hline
\end{tabular}

Analyzing the solutions more in detail, we noticed that the more strategic solutions were supplied in greater numbers by the PPI group by mainly exploiting the guidelines containing Segmentation, Dynamization, Switch to supersystem and Ideality. The improved abilities of these students in exploiting the resources and facing technical contradictions during problem-solving activities could be justified by the training during the PPI course. In fact, the solutions for overcoming contradictions are typically the most focused within the operative time and space. According to TRIZ separations in space and time, solving a contradiction means to exploit a solution only when and where it is really required. On the contrary, other problem-solving actions are usually more extensive, pervasive and greedy for resources.

\subsubsection{Testing HP.2 Are the Guidelines Understandable and Useful?}

Table 3 reports the results about the evaluation of HP. 2 for PPI and PLM groups carried out by analyzing the data from questionnaire. Only answers from the students of the test groups that really applied all parts of the guidelines during the test were considered.

Table 3. Results about the tests for HP.2.

\begin{tabular}{|c|c|c|c|c|}
\hline & \multicolumn{2}{|c|}{$\begin{array}{c}\text { PPI Group } \\
\text { 20 Students from Test Group }\end{array}$} & \multicolumn{2}{|c|}{$\begin{array}{c}\text { PLM Group } \\
16 \text { Students from Test Group }\end{array}$} \\
\hline & Comprehen-sibility & Usefulness & Comprehen-sibility & Usefulness \\
\hline WHEN & $100 \%$ & $100 \%$ & $100 \%$ & $88 \%$ \\
\hline WHAT & $100 \%$ & $100 \%$ & $100 \%$ & $88 \%$ \\
\hline HOW-Generic suggestions & $80 \%$ & $70 \%$ & $63 \%$ & $75 \%$ \\
\hline HOW-Ressources list & $80 \%$ & $60 \%$ & $75 \%$ & $75 \%$ \\
\hline Overall average & $90 \%$ & $83 \%$ & $85 \%$ & $82 \%$ \\
\hline
\end{tabular}

The obtained results substantially confirm the validity of HP.2, albeit with some reservations. WHEN and WHAT parts are largely comprehensible and useful, while the HOW part is a little less understandable for the PLM group and significantly less useful for the PPI group, especially in the specific part suggestions compared to other parts of the guidelines.

These data can be discussed also considering the comments provided by students of the control group, even if they did not apply the guidelines entirely in practice and the free comments.

The good results of the WHEN and WHAT parts provided by PPI students confirm that they support the focusing of the solution in a much more pronounced way than TRIZ, since they appreciate these parts more than the suggestion themselves (HOWs). In addition, from the comments and analysis of the solutions, we also comprehended that this is mainly true for the guidelines containing Segmentation, Dynamization, Switch to supersystem and Ideality. 
The lower judgement about comprehensibility provided by PLM students in relation to the generic and resources list of the HOW part is generally linked to their increased technicality, which could hinders their applications especially during the first few uses. On the other hand, by analyzing their solutions, once understood and internalized, those parts allowed them to achieve the greatest inventive leaps, "by expanding the space of solutions outside of your usual creative domain" as reported by a PLM student. In addition, the more difficult comprehensibility of some them by PLM students is also confirmed by the lower qualitative levels and the restricted number of their solutions exploiting the more technical guidelines in comparison with those of the PPI group, from the environmental point of view.

For what concerns usefulness, the PLM group appreciated the HOW part more than the PPI group, by also underlining, through the comments on the questionnaire, that the suggested actions were not part of the patrimony of customary actions that an engineer is led to do. In addition, in the same way, they reported some difficulties in the interpretation of the guidelines descriptions, for which they necessary relied almost exclusively on the examples and case studies attached to the guidelines, by exlaining to have used them as analog triggers both to stimulate the formulation of new ideas and to interpret the theoretical description of the guidelines.

No clear differences between the two groups in using the guidelines based on dematerialization, reuse, recycle, substitute, design for assembly, change the state of aggregation, porosity, merging, increase control emerged by analyzing the provided solutions. Probably, the greater distance of the link with the foundations of the methodology, removes the advantage that the PPI group could have over the other in terms of competitiveness.

A particular case is represented by the guidelines containing "substitute" and "ideality" suggestions. According to the solution, the physical effects (MATCEM) module application led to the most marked differences between the two groups, especially for what concerns numerosity, as shown for the test about HP.1. In this case, TRIZ training in seeking alternative technologies cannot be replaced by a simple summary description, nor by the proposition of effect libraries, and mental disposition appears to count more than personal knowledge. Finally, the consideration of the previous long-term tests, carried out with the students of the previous years, showed that a similar observation for trimming, which needs a lot of training in order to be fully understood. Training in trimming made it possible to simplify the system even where others stop due to psychological inertia. For the same considerations, "segmentation" emerged to be one of the most complicated principles to translate into guidelines. In fact, it ensured excellent results only when it was correctly applied; however, since its philosophy is also to doubling the objects, the result could not always been a more ecological solution. In many cases, the PPI group proposed its implementation with a lower awareness about the environmental impacts than the PLM group. For this reason, the description of this guideline has been modified several times to clarify the real objective to be achieved.

In conclusion, albeit from the comparison between the two groups, two distinct ways of interpreting and understanding the guidelines emerges, the overall positive opinion encourages us in promoting and disseminating this tool.

\subsection{Further Testing Developments}

In addition to the showed test with PPI and PLM groups, another experimentation involved some students from both courses during the degree thesis projects of eco-improvements, carried out with local companies operating in different production sectors (electronic system for telecommunications, machinery for the production of diapers, pelleting machines, facilities for oil \& gas). In all cases, the in-depth work was much greater, the students conducted the eco-assessment under the supervision of the teacher and the head of the company, while the application of the guidelines took place without any supervision.

The guidelines also prompted a consulting company, the WIL-Warrant Innovation Lab, to forge a collaboration with the research group to promote a service to the small- and medium-sized (SME) 
Italian companies, which started in mid-2019. WIL devoted to facilitate and diffuse the systematic innovation in SMEs, through technology transfer and sharing of knowledge, ideas, technologies and methodologies, in order to establish cooperation and partnership with suitable research teams. The risk of developing an ineffective solution, or worse, abandonment the R\&D project, can be reduced supporting the SME in the formulation of technology concepts before outsourcing the development. This specific service includes an initial assessment phase made by experts and a day of problem solving with the company's technical managers following the guidelines. In this case as for the validation test, sector experts select the set of guildelines compatible with the critical issues of the assessment phase. The role of an intermediary between SMEs and guidelines trainer is crucial for the success of this service. SMEs start from an important skepticism towards the usefulness and/or feasibility of a systematic innovation process such as the guidelines. An independent company like Warrant that has been building in time a trust relationship with its customers, becoming a reference partner in those activities that involve an improvement of technology. It has the opportunity to notice if, in the application of the guidelines, the R\&D projects follows the same path repeatedly without reaching the desired solution. The results of this activity will be the subject of further publications when we have a statistically significant number of validated cases.

\section{Conclusions}

This article proposes a set of 59 guidelines that cover all aspects of the product life cycle. Universal guidelines that push the user to modify the existing by applying suggestions and tools working at a very fine and specific level of detail. Compared to many other methods in the literature, the advantage of the proposed one lies precisely in the specificity of the suggestion that approaches the solution without demanding too much creative effort.

To achieve this result, it was necessary to find a fair compromise between the specificity and universality of each guideline in order to use it effectively in any industrial context (automotive, construction, automation, food, etc.). The overcoming of this contradiction is based around the interpretation of 16 actions directly derived from TRIZ but adapted according to the specific context, i.e., a different combination of When, Action and What.

However, it was an extensive revision of TRIZ fundamentals. In fact, TRIZ is used for finding solutions, not necessarily green. In this case, TRIZ-inspired guidelines must also guarantee the environmental sustainability of a solution and must be able to be used by non-expert users.

To push this generalist approach towards green solutions, a very rigorous ontology by with structuring guidelines has been proposed. It reminds the user always where, when and how to intervene by using TRIZ, taking into account the design consequences on the environment.

Indeed, within the text of the guidelines there are indications (and eventually also links to LCA assessment tools) for becoming aware of one's design choices in an environmental key, to know how to apply an inventive suggestion, on which objective and with what specific purpose.

These suggestions can make the user more aware about where his decisions will have the greatest impact, in order to increase the chances for reaching greener solutions. Furthermore, Eco-guidelines were implemented in a web portal, http://chsp.altervista.org/EcodesignMap/index.html, where they can be easily managed as a checklist also by novice users without any previous competence.

We make the whole method available with the hope that the scientific community can benefit from it and increase the audience of those who can make tests and comparisons with other alternative methods.

The experimentation guidelines on real case studies from small and medium enterprises has provided several encouraging results with the students, to the point of consolidating their standard application procedure directly in the company, in collaboration with a consulting company.

At present, these guidelines are used as a checklist, but they could be also integrated in more complex framework, within an LCA assessment platform.

Author Contributions: Conceptualization: D.R.; methodology: D.R. and C.S.; data curation: C.S.; writingoriginal draft preparation, D.R. and C.S. All authors have read and agreed to the published version of the manuscript. 
Funding: This research received no external funding.

Acknowledgments: We would like to express our gratitude to Eleonora Tandoi and Paolo Carrara from Warrant Innovation LAB for their continuous encouragement to think about research products not only as a tool for spreading knowledge but also as a means to solve those problems that small companies face every day.

Conflicts of Interest: The authors declare no conflict of interest.

\section{References}

1. Ahmad, S.; Wong, K.Y.; Tseng, M.L.; Wong, W.P. Sustainable product design and development: A review of tools, applications and research prospects. Resour. Conserv. Recycl. 2018, 132, 49-61. [CrossRef]

2. Rossi, M.; Germani, M.; Zamagni, A. Review of ecodesign methods and tools. Barriers and strategies for an effective implementation in industrial companies. J. Clean. Prod. 2016, 129, 361-373. [CrossRef]

3. Byggeth, S.; Hochschorner, E. Handling trade-offs in ecodesign tools for sustainable product development and procurement. J. Clean. Prod. 2006, 14, 1420-1430. [CrossRef]

4. Vallet, F.; Eynard, B.; Millet, D.; Mahut, S.G.; Tyl, B.; Bertoluci, G. Using Eco-Design tools: An overview of experts' practices. Des. Stud. 2013, 34, 345-377. [CrossRef]

5. Russo, D.; Serafini, M.; Rizzi, C. Comparison and classification of eco improvement methods. In Proceedings of the DS 80-1 20th International Conference on Engineering Design (ICED 15), Milan, Italy, 27-30 July 2015.

6. Poulikidou, S. Literature Review: Methods and Tools for Environmentally Friendly Product Design and Development: Identification of Their Relevance to the Vehicle Design; KTH Royal Institute of Technology: Stockholm, Sweden, 2012.

7. Saravia-Pinilla, M.H.; Daza-Beltrán, C.; García-Acosta, G. A comprehensive approach to environmental and human factors into product/service design and development. A review from an ergoecological perspective. Appl. Ergon. 2016, 57, 62-71. [CrossRef]

8. Baumann, H.; Boons, F.; Bragd, A. Mapping the green product development field: Engineering, policy and business perspectives. J. Clean. Prod. 2002, 10, 409-425. [CrossRef]

9. Bey, N.; Hauschild, M.Z.; McAloone, T.C. Drivers and barriers for implementation of environmental strategies in manufacturing companies. CIRP Ann. 2013, 62, 43-46. [CrossRef]

10. Boks, C. The soft side of ecodesign. J. Clean. Prod. 2006, 14, 1346-1356. [CrossRef]

11. Johansson, G. Success factors for integration of ecodesign in product development: A review of state of the art. Environ. Manag. Health 2002, 13, 98-107. [CrossRef]

12. Handfield, R.B.; Melnyk, S.A.; Calantone, R.J.; Curkovic, S. Integrating environmental concerns into the design process: The gap between theory and practice. IEEE Trans. Eng. Manag. 2001, 48, 189-208. [CrossRef]

13. Russo, D.; Regazzoni, D.; Montecchi, T. Eco-Design with TRIZ laws of evolution. Procedia Eng. 2011, 9, 311-322. [CrossRef]

14. Sakao, T. A QFD-centred design methodology for environmentally conscious product design. Int. J. Prod. Res. 2007, 45, 4143-4162. [CrossRef]

15. Yang, C.J.; Chen, J.L. Accelerating preliminary eco-innovation design for products that integrates case-based reasoning and TRIZ method. J. Clean. Prod. 2011, 19, 998-1006. [CrossRef]

16. Russo, D.; Rizzi, C.; Montelisciani, G. Inventive guidelines for a TRIZ-based Eco-Design matrix. J. Clean. Prod. 2014, 76, 95-105. [CrossRef]

17. Germani, M.; Mandolini, M.; Marconi, M.; Morbidoni, A.; Rossi, M. A case-based reasoning approach to support the application of the eco-design guidelines. In Re-Engineering Manufacturing for Sustainability; Springer: Singapore, 2013; pp. 81-86.

18. Altshuller, G.S. Creativity as an Exact Science: The Theory of the Solution of Inventive Problems; Gordon and Breach: London, UK, 1984.

19. Caligiana, G.; Liverani, A.; Francia, D.; Frizziero, L.; Donnici, G. Integrating QFD and TRIZ for innovative design. J. Adv. Mech. Des. Syst. Manuf. 2017, 11, JAMDSM0015. [CrossRef]

20. Song, W.; Sakao, T. A customization-oriented framework for design of sustainable product/service system. J. Clean. Prod. 2017, 140, 1672-1685. [CrossRef]

21. Chen, J.L.; Hung, C. Eco-Innovation by Anticipatory Failure Determination (AFD) Method. In Proceedings of the Design Society: International Conference on Engineering Design; Cambridge University Press: Cambridge, UK, 2019; Volume 1, pp. 3271-3280. 
22. Feniser, C.; Burz, G.; Mocan, M.; Ivascu, L.; Gherhes, V.; Otel, C. The evaluation and application of the TRIZ method for increasing eco-innovative levels in SMEs. Sustainability 2017, 9, 1125. [CrossRef]

23. Fresner, J.; Jantschgi, J.; Birkel, S.; Bärnthaler, J.; Krenn, C. The theory of inventive problem solving (TRIZ) as option generation tool within cleaner production projects. J. Clean. Prod. 2010, 18, 128-136. [CrossRef]

24. Vidal, R.; Salmeron, J.L.; Mena, A.; Chulvi, V. Fuzzy cognitive map-based selection of TRIZ (theory of inventive problem solving) trends for eco-innovation of ceramic industry products. J. Clean. Prod. 2015, 107, 202-214. [CrossRef]

25. Lim, I.S.S. The Effectiveness of TRIZ Tools for Eco-Efficient Product Design. In Research and Practice on the Theory of Inventive Problem Solving (TRIZ); Springer: Cham, Switzerland, 2016; pp. 35-53.

26. Cherifi, A.; Dubois, M.; Gardoni, M.; Tairi, A. Methodology for innovative eco-design based on TRIZ. Int. J. Interact. Des. Manuf. 2015, 9, 167-175. [CrossRef]

27. Chen, J.L.; Chen, W.C. TRIZ based eco-innovation in design for active disassembly. In Advances in Life Cycle Engineering for Sustainable Manufacturing Businesses; Springer: London, UK, 2007; pp. 83-87.

28. Justel, D.; Vidal, R.; Chiner, M. TRIZ applied to innovate in design for disassembly. In Proceedings of the 13th CIRP International Conference on Life Cycle Engineering, Leuven, Belguim, 31 May-2 June 2006; Volume 31, pp. 377-382.

29. Russo, D.; Bersano, G.; Birolini, V.; Uhl, R. European testing of the efficiency of TRIZ in eco-innovation projects for manufacturing SMEs. Procedia Eng. 2011, 9, 157-171. [CrossRef]

30. Kobayashi, H. A systematic approach to eco-innovative product design based on life cycle planning. Adv. Eng. Inform. 2006, 20, 113-125. [CrossRef]

31. Yang, C.J.; Chen, J.L. Forecasting the design of eco-products by integrating TRIZ evolution patterns with CBR and Simple LCA methods. Expert Syst. Appl. 2012, 39, 2884-2892. [CrossRef]

32. Chou, J.R. An ARIZ-based life cycle engineering model for eco-design. J. Clean. Prod. 2014, 66, $210-223$. [CrossRef]

33. Maccioni, L.; Borgianni, Y.; Rotini, F. Sustainability as a value-adding concept in the early design phases? Insights from stimulated ideation sessions. In International Conference on Sustainable Design and Manufacturing; Springer: Cham, Switzerland, 2017; pp. 888-897.

34. Bovea, M.A.D.; Pérez-Belis, V. A taxonomy of ecodesign tools for integrating environmental requirements into the product design process. J. Clean. Prod. 2012, 20, 61-71. [CrossRef]

35. Russo, D.; Serafini, M.; Rizzi, C. Is TRIZ an Ecodesign Method? In International Conference on Sustainable Design and Manufacturing; Springer: Cham, Switzerland, 2016; pp. 525-535.

36. Russo, D.; Montecchi, T.; Caputi, A. Tech-Finder: A Dynamic Pointer to Effects. In Proceedings of the 16th International TRIZ Future Conference, Strasbourg, France, 29-31 October 2018; Volume 1, pp. 79-87.

37. Botas, J.A.; Moreno, J.; Espada, J.J.; Serrano, D.P.; Dufour, J. Recycling of used lubricating oil: Evaluation of environmental and energy performance by LCA. Resour. Conserv. Recycl. 2017, 125, 315-323. [CrossRef]

38. Malmodin, J.; Lundén, D. The energy and carbon footprint of the global ICT and E\&M sectors 2010-2015. Sustainability 2018, 10, 3027.

39. Cortina, M.; Arrizubieta, J.; Ruiz, J.; Ukar, E.; Lamikiz, A. Latest developments in industrial hybrid machine tools that combine additive and subtractive operations. Materials 2018, 11, 2583. [CrossRef]

40. Twede, D.; Selke, S.E.; Kamdem, D.P.; Shires, D. Cartons, Crates and Corrugated Board: Handbook of Paper and Wood Packaging Technology; DEStech Publications, Inc.: Lancaster, UK, 2014.

41. Hassanpour, H.; Sadeghi, M.H.; Rasti, A.; Shajari, S. Investigation of surface roughness, microhardness and white layer thickness in hard milling of AISI 4340 using minimum quantity lubrication. J. Clean. Prod. 2016, 120, 124-134. [CrossRef]

42. Go, T.F.; Wahab, D.A.; Hishamuddin, H. Multiple generation life-cycles for product sustainability: The way forward. J. Clean. Prod. 2015, 95, 16-29. [CrossRef]

43. Hegab, H.A.; Darras, B.; Kishawy, H.A. Towards sustainability assessment of machining processes. J. Clean. Prod. 2018, 170, 694-703. [CrossRef]

44. Brinksmeier, E.; Walter, A.; Janssen, R.; Diersen, P. Aspects of cooling lubrication reduction in machining advanced materials. Proc. Inst. Mech. Eng. Part B J. Eng. Manuf. 1999, 213, 769-778. [CrossRef]

45. Priarone, P.C.; Ingarao, G.; Lunetto, V.; Di Lorenzo, R.; Settineri, L. The role of re-design for Additive Manufacturing on the process environmental performance. Procedia CIRP 2018, 69, 124-129. [CrossRef] 
46. Zhao, L.; Guo, Z.; Wang, Z.; Wang, M. Removal of low-content impurities from Al by super-gravity. Metall. Mater. Trans. B 2010, 41, 505-508. [CrossRef]

47. Tun, M.M.; Juchelkova, D. Assessment of solid waste generation and greenhouse gas emission potential in Yangon city, Myanmar. J. Mater. Cycles Waste Manag. 2018, 20, 1397-1408. [CrossRef]

48. Tang, Y.; Mak, K.; Zhao, Y.F. A framework to reduce product environmental impact through design optimization for additive manufacturing. J. Clean. Prod. 2016, 137, 1560-1572. [CrossRef]

49. Wang, T.; Yao, S.; Tong, Q.; Sui, L. Improved filling condition to reduce casting inclusions using the submerged gate method. J. Manuf. Process. 2017, 27, 108-113. [CrossRef]

50. Zegard, T.; Paulino, G.H. Bridging topology optimization and additive manufacturing. Struct. Multidiscip. Optim. 2016, 53, 175-192. [CrossRef]

51. Hui, L.; Hongbin, G.; Dawei, C. Application of high-speed solenoid valve to the semi-active control of landing gear. Chin. J. Aeronaut. 2008, 21, 232-240. [CrossRef]

52. Keating, S.J.; Gariboldi, M.I.; Patrick, W.G.; Sharma, S.; Kong, D.S.; Oxman, N. 3D printed multimaterial microfluidic valve. PLoS ONE 2016, 11, e0160624. [CrossRef] [PubMed]

53. Wu, R.; Kharaghani, A.; Tsotsas, E. Two-phase flow with capillary valve effect in porous media. Chem. Eng. Sci. 2016, 139, 241-248. [CrossRef]

54. Albanesi, A.E.; Pucheta, M.A.; Fachinotti, V.D. A new method to design compliant mechanisms based on the inverse beam finite element model. Mech. Mach. Theory 2013, 65, 14-28. [CrossRef]

(C) 2020 by the authors. Licensee MDPI, Basel, Switzerland. This article is an open access article distributed under the terms and conditions of the Creative Commons Attribution (CC BY) license (http://creativecommons.org/licenses/by/4.0/). 